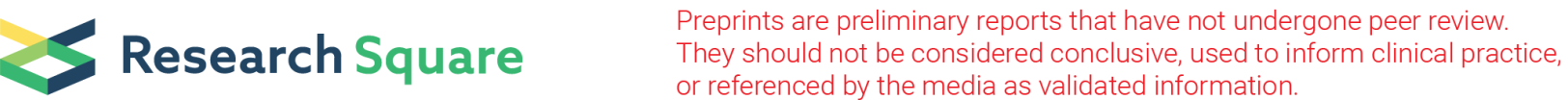

\section{Differential Expression of CD11c Defines Two Types of Tissue-Resident Macrophages with Different Origins in Steady-State Salivary Glands}

Lu Lu

Tohoku University Graduate School of Dentistry

Toshinobu Kuroishi

Tohoku University Graduate School of Dentistry

Yukinori Tanaka

Tohoku University Hospital

Shunji Sugawara ( $\nabla$ shunji.sugawara.d5@tohoku.ac.jp )

Tohoku University Graduate School of Dentistry

\section{Research Article}

Keywords: Gland macrophages, steady-state salivary gland, colony-stimulating factor

Posted Date: June 10th, 2021

DOI: https://doi.org/10.21203/rs.3.rs-590196/v1

License: (9) This work is licensed under a Creative Commons Attribution 4.0 International License.

Read Full License

Version of Record: A version of this preprint was published at Scientific Reports on January 18th, 2022.

See the published version at https://doi.org/10.1038/s41598-022-04941-5. 


\section{Abstract}

Gland macrophages are primed for gland development and functions through interactions within their niche. However, the phenotype, ontogeny, and function of steady-state salivary gland (SG) macrophages remain unclear. We herein identified $\mathrm{CD} 11 \mathrm{c}^{+}$and $\mathrm{CD} 11 \mathrm{c}^{-}$subsets among $\mathrm{CD} 64^{+}$macrophages in steadystate murine SGs. CD11 $\mathrm{c}^{-}$macrophages were predominant in the SGs of embryonic and newborn mice and decreased with advancing age. $\mathrm{CD}_{11} \mathrm{c}^{+}$macrophages were rarely detected in the embryonic period, but rapidly expanded after birth. $C D 11 c^{+}$, but not $C D 11 c^{-}$, macrophage numbers decreased in mice treated with a CCR2 antagonist, suggesting that $\mathrm{CD} 11 \mathrm{c}^{+}$macrophages accumulate from bone marrowderived progenitors in a CCR2-dependent manner, whereas $\mathrm{CD}_{11} \mathrm{c}^{-}$macrophages were derived from embryonic progenitors in SGs. CD $11 c^{+}$and $C D 11 c^{-}$macrophages strongly expressed colony-stimulating factor (CSF)-1 receptor, the injection of an anti-CSF-1 receptor blocking antibody markedly reduced both subsets, and SGs strongly expressed CSF-1, indicating the dependency of SG resident macrophage development on CSF-1. The phagocytic activity of SG macrophages was extremely weak; however, the gene expression profile of SG macrophages indicated that SG macrophages regulate gland development and functions in SGs. These results suggest that SG CD11 $\mathrm{c}^{+}$and $\mathrm{CD} 11 \mathrm{c}^{-}$macrophages are developed and instructed to perform SG-specific functions in steady-state SGs.

\section{Introduction}

Macrophages, monocytes, and dendritic cells (DCs) are members of the mononuclear phagocyte system, which exhibits multifunctional immune responses, and tissue-resident macrophages have a wide variety of functions in mammalian tissues ${ }^{1-3}$. Recent findings indicated that gland macrophages contribute to gland development and functions by regulating stem cell activation, epithelial cell proliferation, hormone synthesis, and secretion through interactions within their niche $e^{4,5}$.

The majority of tissue-resident macrophages are derived from embryonic progenitors and maintained by self-renewal throughout their lifespan. At least three pathways have been implicated in macrophage development ${ }^{1-3}$. Primitive hematopoiesis in the yolk sac gives rise to primitive macrophages without passing through classical monocytic intermediates. Erythro-myeloid progenitors (EMPs) generated in the yolk sac migrate to the fetal liver and generate fetal monocytes. Primitive macrophages seed every tissue and give rise to microglia in the brain, while EMP-derived fetal monocytes infiltrate every other tissue and generate the major pool of adult tissue-resident macrophages by diluting the initial primitive macrophage contribution. Hematopoietic stem cell (HSC)-derived monocytes that emerge from the fetal liver contribute to the long-lived macrophage pool at birth while adult hematopoiesis is only starting in the bone marrow (BM). Adult monocytes contribute to the maintenance of tissue-resident macrophages in some tissues, such as the intestines ${ }^{1,6,7}$.

Salivary glands (SGs) secrete saliva, which includes secretory IgA and other components, into the oral cavity and are important effector sites in the mucosal immune network ${ }^{8}$. In addition to B cells, SGs 
contain $\alpha \beta$ and $\gamma \delta T$ cells, NK cells, and macrophages, and SG tissue may function as an antigen-reactive system with the ability to conduct the last stages of a local secretory immune response against invasive pathogens ${ }^{9} \mathrm{CD} 64$, the high-affinity IgG receptor FcyRI, and Mer tyrosine kinase (MerTK) were recently identified as core macrophage signature markers ${ }^{10,11}$, and by using CD64 as a macrophage marker, we identified $\mathrm{CD} 64^{-} \mathrm{CD} 11 \mathrm{c}^{+}$classical DCs (CDCs) as well as $\mathrm{CD} 64^{+}$macrophages among $\mathrm{CD} 45^{+} \mathrm{MHC}$ class II $(\mathrm{MHClI})^{+}$antigen-presenting cells (APCs) in steady-state murine $\mathrm{SGs}^{12}$. SG cDCs were divided into CD $103^{+} \mathrm{CD} 11 \mathrm{~b}^{-}$type $1 \mathrm{cDCs}$ and $\mathrm{CD} 11 \mathrm{c}^{-} \mathrm{CD} 11 \mathrm{~b}^{+}$type $2 \mathrm{cDCs}$. Both $\mathrm{CDC}$ subsets in SGs markedly expanded in response to the Flt3 ligand, a growth factor of DCs, were replenished by BM-derived precursors, and differentiated from common DC precursors. Furthermore, CD $103^{+} \mathrm{CD}^{1} 1 \mathrm{~b}^{-}$type $1 \mathrm{cDCs}$ possessed an antigen cross-presenting capacity, suggesting that SG CDCs play an important role in maintaining immune homeostasis in SGs. On the other hand, sublingual CDCs preferentially induced regulatory $T$ cells ${ }^{13,14}$. In the course of these studies, we found that $C D 64^{+}$macrophages in SGs comprised $\mathrm{CD} 11 \mathrm{c}^{+}$and $\mathrm{CD} 11 \mathrm{c}^{-}$subsets $^{12}$.

Some characteristics of macrophages in diseased SGs, such as Sjögren's syndrome, have been described $^{15}$, and we previously identified Th17 cells in the SGs of patients with Sjögren's syndrome ${ }^{16}$. However, the phenotype, ontogeny and function of steady-state SG macrophages remain unclear. Therefore, in the present study, we aimed to elucidate the ontogeny and function of SG CD11 $\mathrm{c}^{+}$and CD11 $\mathrm{c}^{-}$steady-state macrophages in mice.

\section{Results}

\section{Phenotype and localization of macrophage subsets in steady-state SGs.}

Cells of the submandibular glands (SMGs) from wild-type mice were isolated by enzymatic digestion using collagenase and analyzed by flow cytometry. By combining the expression of CD64 and CD11C, $\mathrm{CD} 45^{+} \mathrm{MHClI}^{+} \mathrm{APCs}$ in SMGs were separated into $\mathrm{CD} 64^{+}$macrophages and $\mathrm{CD} 64^{-} \mathrm{CD} 11 \mathrm{C}^{+} \mathrm{CDCs}$ (Fig. 1a). $\mathrm{CD}^{+} 4^{+}$macrophages were further classified into the $\mathrm{CD} 11 \mathrm{c}^{+}$and $\mathrm{CD} 11 \mathrm{c}^{-}$subsets. Approximately $90 \%$ of APCs in SMGs were macrophages, and $\mathrm{CD}_{11 \mathrm{c}^{+}}$macrophages were predominant in the SMGs of adult

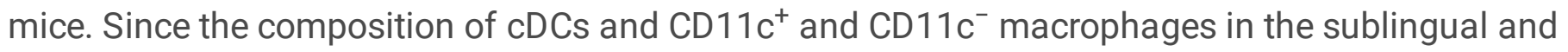
parotid glands was similar to that in SMGs (Fig. 1a, b), we mainly examined SMGs as representative SGs in subsequent experiments.

To clarify the localization of cDCs and macrophages in SGs, we examined their frequencies in whole SMG, enriched ductal, and remaining interstitial fractions. Most macrophages existed in the interstitial region, while cDCs were enriched by approximately 7 -fold in the ductal region (Fig. 1C, d). CD11 ${ }^{+}$ macrophages were predominant in the ductal and interstitial regions; however, the frequency of CD11 $\mathrm{c}^{-}$ macrophages slightly increased in the ductal region (Fig. 1c, e), indicating that most CD11 $\mathrm{c}^{+}$and CD $11 \mathrm{c}^{-}$ macrophages reside in the interstitial and ductal regions and also that $\mathrm{CDCs}$ and some $C D 11 \mathrm{c}^{-}$ macrophages are potently associated with the ductal region. 
$\mathrm{CD}_{11} \mathrm{c}^{+}$and $\mathrm{CD} 11 \mathrm{c}^{-}$macrophages equally expressed $\mathrm{MHCl}, \mathrm{CD} 11 \mathrm{~b}$, the macrophage marker $\mathrm{F} 4 / 80$, and CD14 (Fig. 1f). CD11 $\mathrm{c}^{-}$macrophages also more strongly expressed MerTK and the mannose receptor CD206 than CD11 $\mathrm{c}^{+}$macrophages, while CX3CR1 was strongly expressed in CD11 $\mathrm{c}^{+}$macrophages. These results indicated that macrophages exist as predominant APCs in the steady-state SGs of adult mice and that SG macrophages comprise $\mathrm{CD} 11 \mathrm{c}^{+}$and $\mathrm{CD} 11 \mathrm{c}^{-}$subsets, which may have different ontogenies and functions.

\section{Age-dependent transition of macrophage subsets in steady-state SMGs.}

To examine the ontogeny of SG macrophage subsets, we analyzed macrophages in steady-state SMGs from mice at E13.5, E17.5, and E19 (embryo) and at 3 days (newborn) and 1, 2, 3, 4, 8, 12, and 24 weeks after birth by flow cytometry. The results obtained showed that CD $11 \mathrm{c}^{-}$macrophages were a major population in the SMGs of the embryonic period and newborn mice, and then decreased with advancing age after birth (Fig. 2a). Inversely, CD11 $\mathrm{c}^{+}$macrophages were rarely detected in the SMGs of the embryonic period and newborn mice, and then rapidly expanded with advancing age. The proportion of CD11 $\mathrm{c}^{+}$macrophages in young ( 4 weeks old) mice was similar to that in adult ( 8 to 24 weeks old) mice (Fig. 2b). The cell numbers of $\mathrm{CD} 11 \mathrm{c}^{+}$and $\mathrm{CD} 11 \mathrm{c}^{-}$macrophages both rapidly expanded concomitantly with the growth of SMGs at 4 weeks (Fig. 2c); however, the number of $\mathrm{CD}_{11 \mathrm{c}^{-}}$macrophages per tissue weight slightly decreased after birth (Fig. 2d). In addition, the expression of $\mathrm{MHCl}$ in $\mathrm{CD} 11 \mathrm{c}^{+}$and $\mathrm{CD} 11 \mathrm{c}^{-}$ macrophages increased 2 and 4 weeks after birth, respectively (Fig. 2e). Therefore, marked changes in the composition of macrophage subsets and their maturation status occurred with SG development.

\section{HSC dependence of SMG CD11C ${ }^{+}$macrophages.}

The result showing that $C D 11 \mathrm{c}^{+}$macrophages expanded in SMGs after birth suggested that $\mathrm{CD} 11 \mathrm{c}^{+}$ macrophages differentiated from BM-derived monocytes. Since the emigration of monocytes from BM requires signals mediated by the chemokine receptor CCR2 ${ }^{17}$, we examined the effects of a CCR2 antagonist on the accumulation of macrophages in steady-state SMGs. The treatment of mice with a CCR2 antagonist reduced the percentage of CD11 $\mathrm{c}^{+}$macrophages (Fig. 3a, b). The number of CD11 $\mathrm{c}^{+}$ macrophages was also significantly reduced by the treatment, whereas that of $C D 11 c^{-}$macrophages was not (Fig. 3c). Furthermore, 21 days after CD45.1 ${ }^{+}$BM cell transplantation into sublethal irradiated CD45. $2^{+}$mice, differentiated donor-derived macrophages were mainly the CD11 $\mathrm{c}^{+}$phenotype (Fig. $3 \mathrm{~d}, \mathrm{e}$ ). These results suggest that $\mathrm{CD} 11 \mathrm{c}^{+}$macrophages mainly accumulated from HSC-derived progenitors in a CCR2-dependent manner, while CD11 $\mathrm{c}^{-}$macrophages were derived from embryonic progenitors and selfrenewed in SGs.

\section{Colony-stimulating factor (CSF)-1-dependent accumulation of SMG macrophages.}

CSF-1 or CSF-2 is indispensable for the development and homeostasis of tissue-resident macrophages. CSF-1 is produced in the spleen and capable of maintaining splenic macrophages locally, ${ }^{18}$ whereas the 
production of CSF-2 in the lungs is required for the development of alveolar macrophages ${ }^{19,20}$. To examine whether CSF-1 or CSF-2 influences the development of SG macrophages, SMG CD11 ${ }^{+}$and CD11 $\mathrm{c}^{-}$macrophages and splenic and alveolar macrophages were sorted (Supplementary Fig. S1), and the expression of Csf1r and Csf2rb mRNA was examined to assess CSF-1 receptor (CSF-1R) and CSF-2R expression in these macrophages. Splenic and alveolar macrophages were used as positive controls for the expression of $C s f 1 r$ and $C s f 2 r b$ mRNA, respectively. The results obtained showed that SMG CD11 ${ }^{+}$ and CD11 $\mathrm{c}^{-}$macrophages strongly expressed $\mathrm{Csf1r}$, but not Csf2rb (Fig. 4a). We also measured CSF-1 and CSF-2 expression levels in SMGs. Homogenates of the spleen and lungs were used as positive controls for the expression of Csf1 and Csf2 mRNA, respectively. The expression of Csf1 was significantly stronger in SMGs than in the spleen, whereas that of Csf2 was significantly weaker in SMGs than in the lungs (Fig. 4b), suggesting the dependency of SG CD11 $\mathrm{c}^{+}$and $\mathrm{CD} 11 \mathrm{c}^{-}$macrophage development on CSF-1. To confirm this, an anti-CSF-1R blocking antibody was intraperitoneally injected. The results obtained showed that the percentages and total cell numbers of SMG CD11 $c^{+}$and CD $11 c^{-}$ macrophages markedly decreased (Fig. 4c, d), and the injection of anti-CSF-1R did not influence the number of SMG CDCs (Fig. 4d) or body and SMG weights (Fig. 4e, f). Collectively, these results clearly indicate that the production of CSF-1 in SGs plays a critical role in CSF-1R-expressing SG resident macrophage development.

\section{Mastication does not affect the development of SMG macrophages.}

Since the number of CD11 $\mathrm{c}^{+}$macrophages increased in mice aged 2-4 weeks (Fig. 2a, b) when they began to be weaned and eat the standard diet, we investigated whether mastication affected the development of $\mathrm{CD} 11 \mathrm{c}^{+}$macrophages. One-week-old mice and their mothers were fed standard pellets or a powdered diet. After 8 weeks, the proportion of $\mathrm{CD} 11 \mathrm{c}^{+}$and $\mathrm{CD} 11 \mathrm{c}^{-}$macrophages in SMGs was analyzed. No significant differences were observed in the percentage or number of $\mathrm{CD}_{11 \mathrm{c}^{+}}$macrophages between the pellet and powdered diet groups (Fig. 5a-c). Body and SMG weights were also unchanged between the groups (Fig. 5d, e). These results indicated that mastication did not affect the development of $S G$ resident macrophages.

\section{Functional perspectives of SG macrophages.}

The gene expression profiles of SMG CD11 $\mathrm{c}^{+}$macrophages, alveolar macrophages, and splenic macrophages were examined and compared. SMG CD11 $\mathrm{c}^{-}$macrophages were not assessed because their number was too small for analysis. Hierarchical clustering demonstrated that SMG CD11c ${ }^{+}$ macrophages did not cluster with splenic and alveolar macrophages (Fig. 6a), suggesting a weak relationship between these macrophages. We then compared the expression of 39 core macrophage signature genes ${ }^{10}$. Normalized relative gene expression demonstrated that SMG CD 11 $\mathrm{c}^{+}$macrophages expressed lower levels of Arsg encoding arylsulfatase G, MerTK encoding MerTK, and PId3 encoding phospholipase D3 (Fig. 6b). MerTK is a receptor for apoptotic cell uptake ${ }^{21}$, and arylsulfatase $\mathrm{G}$ and phospholipase D3 are lysosomal enzymes 22,23 , suggesting that SG macrophages exhibit weak 
phagocytic activity. An in vitro analysis showed that although SMG $\mathrm{CD} 11 \mathrm{c}^{-}$macrophages phagocytosed BioParticle more efficiently than SMG CD11 $\mathrm{c}^{+}$macrophages, the phagocytic activities of SMG CD11 $\mathrm{c}^{+}$ and $\mathrm{CD} 11 \mathrm{C}^{-}$macrophages were markedly weaker than that of peritoneal macrophages (Fig. $6 \mathrm{c}$ ).

Phagocytosis by macrophages was abrogated by the addition of cytochalasin D, the F-actin disrupter ${ }^{24}$, to the culture.

A gene ontology (GO) pathway analysis identified 2988 genes that were up-regulated in SMG CD 11 $\mathrm{c}^{+}$ macrophages (Fig. 6d), which displayed enrichment for pathways involved in developmental processes, such as anatomical structure morphogenesis, anatomical structure development, developmental process, tissue development, system development, and single-organism developmental process, and migration processes including locomotion and the regulation of cellular components, cell migration, and cell motility (Fig. 6e). In contrast, 1401 genes were down-regulated in SMG CD11 ${ }^{+}$macrophages (Fig. 6f), which displayed enrichment for pathways involved in immune system processes, single organism processes, the positive regulation of biological processes, and the positive regulation of cellular processes (Fig. $6 \mathrm{~g}$ ). In comparisons with alveolar and splenic macrophages, 59 and 20 transcription factors were up- and down-regulated by more than 5-fold, respectively, in SMG CD $11 \mathrm{c}^{+}$macrophages (Fig. 6h, i). Therefore, the transcription profile is unique to SG macrophages, indicating that they are specifically primed to function in SGs.

\section{Discussion}

The present study showed that $\mathrm{CD} 64^{+}$macrophages among $\mathrm{CD} 45^{+} \mathrm{MHCII}{ }^{+} \mathrm{APC}$ in murine SGs were phenotypically divided into $\mathrm{CD}_{11 \mathrm{c}^{+}}$and $\mathrm{CD} 11 \mathrm{c}^{-}$subsets. $\mathrm{CD} 11 \mathrm{c}^{-}$macrophages dominantly existed in the SGs of the embryonic period and neonatal mice and decreased after birth. In contrast, $C D 11 c^{+}$ macrophages appeared after birth in SGs and rapidly expanded with advancing age. Since CD $11 \mathrm{c}^{+}$ alveolar macrophages develop from CD11 $\mathrm{c}^{-}$fetal monocytes in the lungs ${ }^{19}$, SG CD11 $\mathrm{c}^{-}$macrophages may give rise to $\mathrm{CD} 11 \mathrm{c}^{+}$macrophages after birth. However, the present study showed that $\mathrm{CD} 11 \mathrm{c}^{+}$ macrophages expanded in a CCR2-dependent manner and differentiated from BM-derived progenitors, while $\mathrm{CD} 11 \mathrm{c}^{-}$macrophages did not change in number following a treatment with a CCR2 antagonist and only weakly differentiated from transferred BM cells. A mass cytometric analysis suggested that fetalderived tissue-resident macrophages in the mammary gland are CD206 ${ }^{\mathrm{Hi}}$ cells ${ }^{25}$, and SG CD $11 \mathrm{c}^{-}$ macrophages preferentially expressed CD206 (Fig. 1f). Therefore, it is conceivable that SG CD11 ${ }^{-}$ macrophages are mainly derived from fetal progenitors and self-renewed in SGs, while CD11 ${ }^{+}$ macrophages differentiated from BM-derived progenitors after birth in SGs.

The present results demonstrated that macrophages in embryo SMGs were $\mathrm{CD}_{11 \mathrm{c}^{-} \mathrm{MHCII}}$, which is consistent with previous findings showing that embryo-derived cardiac macrophages present at birth were $\mathrm{CX} 3 \mathrm{CR} 1^{+} \mathrm{MHCII}^{-26}$. This study also revealed that the expression of $\mathrm{MHCll}$ in SG macrophages started to increase after birth. The expression of $\mathrm{MHCll}$ is fine-tuned to function in various parameters, 
including developmental stages, the activation status, and exposure to extracellular stimuli, and $\mathrm{MHCll}$ loads antigenic peptides and guides the development and activation of antigen-specific CD $4^{+} \mathrm{T}$ cells ${ }^{27,28}$. Therefore, it is conceivable that SG macrophages acquire the ability of specific antigen presentation after birth.

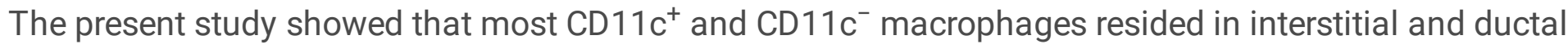
regions and that $\mathrm{CDCs}$ and some $\mathrm{CD} 11 \mathrm{c}^{-}$macrophages were strongly associated with the ductal region. The result may not be consistent with recent findings showing that $C D 11 c^{+}$macrophages were associated with acini and ducts in SGs using the CD11c-yellow fluorescent protein (YFP) reporter strain ${ }^{29}$. We attributed this discrepancy to differences in the gating strategy. We initially separated $\mathrm{CD} 45^{+} \mathrm{MHCl}^{+}$ APCs in SGs into CD $64^{+}$macrophages and $\mathrm{CD} 64^{-} \mathrm{CD} 11 \mathrm{c}^{+} \mathrm{CDCs}$ while they gated CD11c-YFP, which

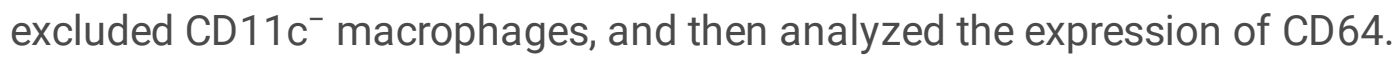

The present study showed that the development of SG CD11 $\mathrm{c}^{+}$and $\mathrm{CD} 11 \mathrm{c}^{-}$macrophages depended on CSF-1R signaling, which supports CSF-1 being released from the serous acinar cells of SGs to function in the survival, recruitment, and proliferation of SG macrophages ${ }^{4,5,30,31}$. The results obtained also showed that SG CD11 $\mathrm{c}^{+}$macrophages expanded rapidly in mice aged 2-4 weeks when they began to be weaned and eat the standard diet. Since mechanical stress has been suggested to explain the replacement of embryo-derived macrophages by circulating monocyte-derived macrophages ${ }^{7,26}$, we examined whether mastication influenced the development of SG CD11 $\mathrm{c}^{+}$macrophages; however, the powdered diet did not change the proportion of SG resident macrophages. Previous studies also demonstrated that intestinal commensal microbiota controlled macrophage turnover ${ }^{6,7}$, therefore, oral commensal microbiota may promote SG CD11 $\mathrm{c}^{+}$macrophage development. In the intestines, TGF- $\beta$ was identified as indispensable for the differentiation of monocytes into macrophages ${ }^{32}$. Therefore, further studies are needed to identify the SG microenvironmental factors that control macrophage development in order to maintain SG homeostasis.

In mammary glands, which are exocrine glands similar to SGs, macrophages distribute during distinct phases of development and remodeling ${ }^{33}$, and ductal macrophages survey the mammary epithelium and facilitate tissue remodeling ${ }^{34}$, indicating that mammary gland macrophages play an essential role in gland development. However, there is still no clear evidence to show that macrophages contribute to SG development. In mouse SMG morphogenesis, the gland is highly branched by E14, and functional differentiation begins at E15 and continues to birth ${ }^{35}$. The present study showed that CD11 $\mathrm{c}^{-}$ macrophages were already detected at E13.5 (Fig. 2) and potently associated with the ductal region (Fig. 1c-e). Therefore, CD11 $\mathrm{c}^{-}$macrophages may play an essential role in gland morphogenesis in association with the ductal region in fetal SGs. The treatment of SMGs isolated from E12.5 mouse embryos with anti-CSF- 1 or anti-CSF-1R reduced the numbers of $\mathrm{F} 4 / 80^{+}$macrophages and suppressed the development of SMGs; however, the latter effect may be explained by macrophage-independent pathways $^{36}$. The specific depletion of macrophages by novel approaches, such as the use of CD64- 
diphtheria toxin receptor mice, may contribute to a more detailed understanding of the exact role of macrophages in SG morphogenesis.

In conclusion, the present results indicate that fetal macrophages are present in SGs as early as E13.5 for the development of SGs, and that SG macrophages continues to function after birth in steady-state SGs by inducing proliferation of fetal-derived macrophages and receiving supplies from BM-derived progenitors. CD11c is a key marker that distinguishes between BM- and embryonic-derived SG macrophages. The present study showed that the phagocytic activity of SG macrophages was extremely weak; however, the gene expression profile of SMG macrophages suggested that SG macrophages regulate gland development and functions in SGs. This view is partly supported by recent findings indicating that murine SG macrophages allow the patrolling of tissue by tissue-resident memory $\mathrm{CD} 8^{+} \mathrm{T}$ cells for homeostatic organ surveillance ${ }^{29}$, and attenuate radiotherapy-induced dry mouth through the activation of the Hedgehog pathway ${ }^{37}$. The further characterization of SG macrophages is important for evaluating the contribution of SG macrophage subpopulations to SG homeostasis and to the pathology of SG dysfunctions and their therapeutic purposes.

\section{Materials And Methods}

\section{Mice.}

CD45.2 ${ }^{+}$C57BL/6N mice were purchased from CLEA Japan (Tokyo, Japan). Male and female mice were placed into the same cage at 8 p.m. Mice were separated the next morning and regarded as embryonic development day 0.5 (E0.5). Congenic CD 45.1 ${ }^{+}$C57BL/ 6 mice were provided by RIKEN BRC (Tsukuba, Japan). All experiments were approved by the Institutional Animal Care and Use Committee of Tohoku University (approved number: 2017DnA-006) and were performed in accordance with their guidelines and regulations. This study was carried out in compliance with the ARRIVE Essential 10 Guidelines.

\section{Preparation of single-cell suspensions.}

Mice were euthanized with isoflurane and then perfused with $20 \mathrm{ml}$ of phosphate-buffered saline (PBS) through the left ventricle to remove circulating blood. SG cells were purified following previously described protocols ${ }^{12}$, and subjected to a flow cytometric analysis. To enrich ducts, SMGs were digested with collagenase, hyaluronidase, and DNase for $1 \mathrm{~h}$ and pipetted with a 25-ml pipette. Ducts were manually selected using a dissection microscope and processed to single cells as described above. The spleen and lungs were cut into small pieces. Spleen pieces were incubated with $1 \mathrm{mg} / \mathrm{ml}$ of collagenase D (Roche, Basel, Switzerland) and $0.1 \mathrm{mg} / \mathrm{ml}$ of DNase I in RPMl 1640 medium containing $10 \%$ fetal bovine serum (FBS) at $37^{\circ} \mathrm{C}$ for $30 \mathrm{~min}$ with shaking. Spleen cells were depleted of red blood cells by hypotonic lysis. Lung pieces were incubated with $0.4 \mathrm{mg} / \mathrm{ml}$ of collagenase type IV (Sigma-Aldrich, St Louis, MO) in RPMI 1640 medium containing $10 \%$ FBS at $37^{\circ} \mathrm{C}$ for 45 min with shaking.

\section{BM chimera.}


BM cells from congenic CD $45.1^{+}$C57BL/ 6 were collected as previously described ${ }^{12}$. CD $45.2^{+}$recipient mice were sublethally $\mathrm{Y}$-irradiated with a single dose of $5 \mathrm{~Gy}$ and intravenously injected with $2 \times 10^{6}$ CD45. $1^{+}$total BM cells. Chimeric mice were analyzed 3,7 , and 21 days after BM transplantation.

\section{Flow cytometry.}

Flow cytometry was performed as previously described ${ }^{12}$. Cells were treated with an anti-CD 16/32 antibody (2.4G2; produced in-house) to block Fc receptors and then stained with antibodies. The antibodies used were listed in Supplementary Table S1. Dead cells were excluded using DAPI (Dojindo, Kumamoto, Japan). Data were acquired on an LSRFortessa cell analyzer (BD Biosciences, San Jose, CA) and analyzed using FlowJo software (Tree Star, Ashland, OR). Absolute cell numbers were measured by CountBright absolute counting beads (Life Technologies, Carlsbad, CA). Cell sorting was performed using a FACSAria II cell sorter (BD Biosciences). Splenic macrophages were sorted as live gated $\mathrm{CD} 45^{+} \mathrm{B} 220^{-} \mathrm{MHCll}{ }^{+} \mathrm{F} 4 / 80^{+} \mathrm{CD} 64^{+} \mathrm{CD} 11 \mathrm{c}^{\text {int }}$ cells. Alveolar macrophages were sorted as live gated $\mathrm{CD} 45^{+} \mathrm{MHCll}{ }^{\text {low }}$ Siglec- $\mathrm{F}^{+} \mathrm{CD} 64^{+} \mathrm{F} 4 / 80^{+} \mathrm{CD} 11 \mathrm{c}^{+} \mathrm{CD} 11 \mathrm{~b}^{-}$cells (Supplementary Fig. S1).

\section{Quantitative real-time PCR.}

Total RNA from tissues and sorted macrophages was extracted by the RNeasy Mini Kit (QIAGEN, Hilden, Germany). Complement DNA (cDNA) was synthesized using a Transcriptor First Strand cDNA Synthesis Kit (Roche). Quantitative RT-PCR was performed using the SYBR Select Master Mix and StepOnePlus realtime PCR system (Applied Biosystems, Waltham, MA). The primers used for quantitative RT-PCR are shown in Supplementary Table S2. Gene expression was normalized to $\beta$-actin mRNA levels.

CCR2 antagonist treatment in vivo.

Newborn mice were administered $50 \mathrm{mg} / \mathrm{kg}$ of the CCR2 antagonist propagermanium (Sigma-Aldrich) via daily oral gavage and $0.1 \mathrm{mg} / \mathrm{ml} \mathrm{PG}$ in drinking water from postnatal day 3 for 4 weeks. The vehicle control group was given an equal volume of tap water. Body and SMG weights were measured and SMG cells were subjected to flow cytometry.

\section{Anti-CSF-1R treatment in vivo.}

Anti-CSF-1R mAb was purified from the ascites of nude mice injected with AFS98 hybridoma cells (Riken BRC, Japan). C57BL/ 6 female mice were injected with 2, 0.5 , and $0.5 \mathrm{mg}$ of anti-CSF-1 R mAb in $300 \mu \mathrm{l}$ sterile PBS by an intraperitoneal injection on days 0,1 , and 2, respectively, and then analyzed on day 5 .

\section{Assessment of phagocytosis in vitro.}

SMG or peritoneal cells were stained with anti-CD45 (clone 30-F11)-APC (BioLegend, San Diego, CA), and then purified using the EasySep Mouse APC Selection Kit (STEMCELL Technologies, Canada). The pHrodo $^{\text {TM }}$ Green Escherichia coli BioParticles conjugate for phagocytosis (Thermo Fisher Scientific) was used as indicated by the manufacturer's protocol. One hundred microliters of the pHrodo ${ }^{\mathrm{TM}}$ Green $E$. coli 
BioParticle suspension and purified SMG or peritoneal CD $45^{+}$cells $\left(1 \times 10^{6}\right)$ were cocultured at $37^{\circ} \mathrm{C}$ for 1 h. To inhibit phagocytosis, $5 \mu \mathrm{g} / \mathrm{ml}$ cytochalasin D (Wako Pure Chemical, Osaka, Japan) was added to culture media for $45 \mathrm{~min}$ as a negative control. Cells were further analyzed by flow cytometry after the incubation.

\section{Microarray analysis.}

Macrophage subsets were sorted from the SMG, lung, and splenic single-cell suspensions of C57BL/ $6 \mathrm{~N}$ mice using the FACS Aria II cell sorter (BD Biosciences). Gating strategies are shown in Supporting Information Fig. 1. The total RNA of macrophages was then extracted using a RNeasy Mini Kit (Qiagen). Cyanine-3-labeled cRNA was amplified from 50 ng of total RNA using a Low Input Quick Amp Labeling Kit (Agilent Technologies, Santa Clara, CA). Gene expression profiles were analyzed using SurePrint G3 Mouse GE 8x60K ver.2.0 (Agilent Technologies). Microarray slides were scanned using a Microarray Scanner (Agilent Technologies), and raw fluorescence intensities were quantified and normalized using Feature Extraction software 12.0.3.1 (Agilent Technologies). Raw signal data were processed using Feature Extraction software 12.0.3.1 (Agilent Technologies). Processed data were analyzed using GeneSpring ver. 13.1.1 (Agilent Technologies) or R (R Foundation for Statistical Computing, Vienna, Austria). The microarray data analysis was supported by Hokkaido System Science (Sapporo, Japan). SMG macrophages from eighteen mice or the remaining macrophage subsets from six mice were pooled as one experimental sample, and three independent samples were performed in the microarray analysis.

\section{Statistical analysis.}

Experimental values are expressed as means \pm s.d. Statistical analyses were performed using Prism 7.02 software (GraphPad Software, San Diego, CA) as described in the figure legends. Values of $P<0.05$ were considered to indicate significance.

\section{Declarations}

Acknowledgments

We would like to thank Dr. Satoshi Fukumoto (Tohoku University Graduate School of Dentistry, Sendai, Japan) for his assistance with embryonic SMG isolation. We also thank the Biomedical Research Core of the Tohoku University Graduate School of Medicine for the use of its equipment. This work was supported by Grants-in-Aid for Scientific Research (B) (15H05011 and 19H03823 to S. S.) from the JSPS, Japan.

Author contributions

T.K., Y.T., and S.S. conceived the study, L.L. T.K., Y.T., and S.S. designed the experiments. L.L. performed key experiments, T.K. and Y.T. helped with implementation, and L.L. T.K., Y.T., and S.S. performed data analysis and interpretation. L.L. and S.S. wrote the manuscript. S.S. supervised the project and obtained 
funding to support the project. All authors read, reviewed, and approved the final manuscript to be published.

Competing interest

The authors declare no competing interests.

\section{References}

1. Ginhoux, F. \& Guilliams, M. Tissue-Resident Macrophage Ontogeny and Homeostasis. Immunity 44, 439-449 (2016).

2. Hoeffel, G. \& Ginhoux, F. Fetal monocytes and the origins of tissue-resident macrophages. Cell. Immunol. 330, 5-15 (2018).

3. Bonnardel, J. \& Guilliams, M. Developmental control of macrophage function. Curr. Opin. Immunol. 50, 64-74 (2018).

4. Guilliams, M., Thierry, G. R., Bonnardel, J. \& Bajenoff, M. Establishment and Maintenance of the Macrophage Niche. Immunity 52, 434-451 (2020).

5. Bijnen, M. \& Bajénoff, M. Gland Macrophages: Reciprocal Control and Function within Their Niche. Trends Immunol. 42, 120-136 (2021).

6. Bain, C. C. et al. Constant replenishment from circulating monocytes maintains the macrophage pool in the intestine of adult mice. Nat. Immunol. 15, 929-937 (2014).

7. Bain, C. C. \& Schridde, A. Origin, Differentiation, and Function of Intestinal Macrophages. Front. Immunol. 9, 2733 (2018).

8. Mega, J., McGhee, J. R. \& Kiyono, H. Cytokine- and Ig-producing T cells in mucosal effector tissues: analysis of IL-5- and IFN-gamma-producing T cells, T cell receptor expression, and IgA plasma cells from mouse salivary gland-associated tissues. J. Immunol. 148, 2030-2039 (1992).

9. Oudghiri, M., Seguin, J. \& Deslauriers, N. The cellular basis of salivary immunity in the mouse: incidence and distribution of B cells, $T$ cells and macrophages in single-cell suspensions of the major salivary glands. Eur. J. Immunol. 16, 281-285 (1986).

10. Gautier, E. et al. Gene-expression profiles and transcriptional regulatory pathways that underlie the identity and diversity of mouse tissue macrophages. Nat. Immunol. 13, 1118-1128 (2012).

11. Tamoutounour, S. et al. CD64 distinguishes macrophages from dendritic cells in the gut and reveals the Th1-inducing role of mesenteric lymph node macrophages during colitis. Eur. J. Immunol. 42, 3150-3166 (2012).

12. Lu, L., Tanaka, Y., Ishii, N., Sasano, T. \& Sugawara, S. CD $103^{+} \mathrm{CD} 11 \mathrm{~b}^{-}$salivary gland dendritic cells have antigen cross-presenting capacity. Eur. J. Immunol. 47, 305-313 (2017).

13. Tanaka, Y. et al. Oral $C D 103^{-} \mathrm{CD} 11 \mathrm{~b}^{+}$classical dendritic cells present sublingual antigen and induce Foxp $3^{+}$regulatory T cells in draining lymph nodes. Mucosal Immunol. 10, 79-90 (2017). 
14. Tanaka, Y., Fukumoto, S. \& Sugawara, S. Mechanisms underlying the induction of regulatory T cells by sublingual immunotherapy. J. Oral Biosci. 61, 73-77 (2019).

15. Ma, W. T., Gao, F., Gu, K. \& Chen, D. K. The role of monocytes and macrophages in autoimmune diseases: A comprehensive review. Front. Immunol. 10, 1140 (2019).

16. Sakai, A., Sugawara, Y., Kuroishi, T., Sasano, T. \& Sugawara, S. Identification of IL-18 and Th17 cells in salivary glands of patients with Sjögren's syndrome, and amplification of IL-17-mediated secretion of inflammatory cytokines from salivary gland cells by IL-18. J. Immunol. 181, 2898-2906 (2008).

17. Serbina, N. V. \& Pamer, E. G. Monocyte emigration from bone marrow during bacterial infection requires signals mediated by chemokine receptor CCR2. Nat Immunol. 7, 311-317 (2006).

18. Cecchini, M. et al. Role of colony stimulating factor- 1 in the establishment and regulation of tissue macrophages during postnatal development of the mouse. Development 120, 1357-1372 (1994).

19. Guilliams, M. et al. Alveolar macrophages develop from fetal monocytes that differentiate into longlived cells in the first week of life via GM-CSF. J. Exp. Med. 210, 1977-1992 (2013).

20. Trapnell, B. C. \& Whitsett, J. A. Gm-CSF regulates pulmonary surfactant homeostasis and alveolar macrophage-mediated innate host defense. Annu. Rev. Physiol. 64, 775-802 (2002).

21. Lemke, G. How macrophages deal with death. Nat. Rev. Immunol. 19, 539-549 (2019).

22. Lübke, T. \& Damme, M. Lysosomal sulfatases: a growing family. Biochem. J. 477, 3963-3983 (2020).

23. Gonzalez, A. C. et al. Unconventional Trafficking of Mammalian Phospholipase D3 to Lysosomes. Cell Rep. 22, 1040-1053 (2018).

24. Brenner, S. L. \& Korn, E. D. Substoichiometric concentrations of cytochalasin D inhibit actin polymerisation. J. Biol. Chem. 254, 9982-9985 (1979).

25. Jäppinen, N. et al. Fetal-derived macrophages dominate in adult mammary glands. Nat. Commun. 10, 281 (2019).

26. Molawi, K. et al. Progressive replacement of embryo-derived cardiac macrophages with age. J. Exp. Med. 211, 2151-2158 (2014).

27. Reith, W., LeibundGut-Landmann, S. \& Waldburger, J. M. Regulation of MHC class II gene expression by the class II transactivator. Nat. Rev. Immunol. 5, 793-806 (2005).

28. Roche, P. A. \& Furuta, K. The ins and outs of MHC class II-mediated antigen processing and presentation. Nat. Rev. Immunol. 15, 203-216 (2015).

29. Stolp, B. et al. Salivary gland macrophages and tissue-resident CD $8^{+} T$ cells cooperate for homeostatic organ surveillance. Sci. Immunol. 5, eaaz4371 (2020).

30. Ryan, G. R. et al. Rescue of the colony-stimulating factor 1 (CSF-1)-nullizygous mouse $\left(C s f 1^{O P} / C s f 1^{\circ D}\right.$ ) phenotype with a CSF-1 transgene and identification of sites of local CSF-1 synthesis. Blood 98, 74-84 (2001).

31. Abboud, S. L., Bunegin, M., Ghosh-Choudhury, N. \& Woodruff, K. Analysis of the mouse CSF-1 gene promoter in a transgenic mouse model. J. Histochem. Cytochem. 51, 941-949 (2003). 
32. Schridde, A. et al. Tissue-specific differentiation of colonic macrophages requires TGF $\beta$ receptormediated signaling. Mucosal Immunol. 10, 1387-1399 (2017).

33. Stewart, T. A., Hughes, K., Hume, D. A. \& Davis, F. M. Developmental Stage-Specific Distribution of Macrophages in Mouse Mammary Gland. Front. Cell Dev. Biol. 7, 250 (2019).

34. Dawson, C. A. et al. Tissue-resident ductal macrophages survey the mammary epithelium and facilitate tissue remodeling. Nat. Cell Biol. 22, 546-558 (2020).

35. Patel, V. N. \& Hoffman, M. P. Salivary gland development: a template for regeneration. Semin. Cell Dev. Biol. 25-26, 52-60 (2014).

36. Sathi, G. A. et al. MCSF orchestrates branching morphogenesis in developing submandibular gland tissue. J. Cell Sci. 130, 1559-1569 (2017).

37. Zhao, Q. et al. Transient Activation of the Hedgehog-Gli Pathway Rescues Radiotherapy-Induced Dry Mouth via Recovering Salivary Gland Resident Macrophages. Cancer Res. 80, 5531-5542 (2020).

\section{Figures}


a SMG

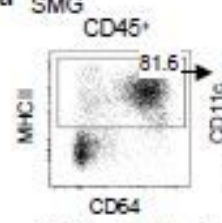

Sublingual gland

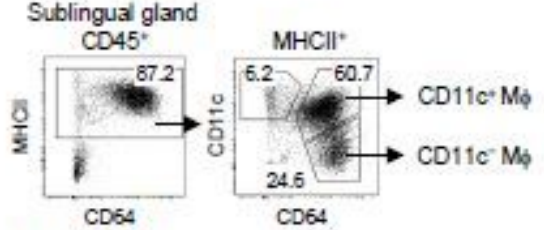

Parotid gland

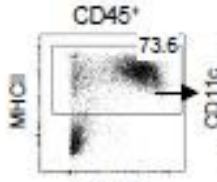

CD64

c SMG

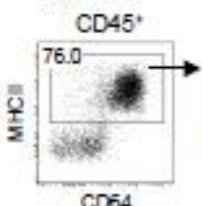

$\mathrm{CD64}$

Interstitial region

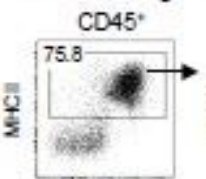

CD64

Duct
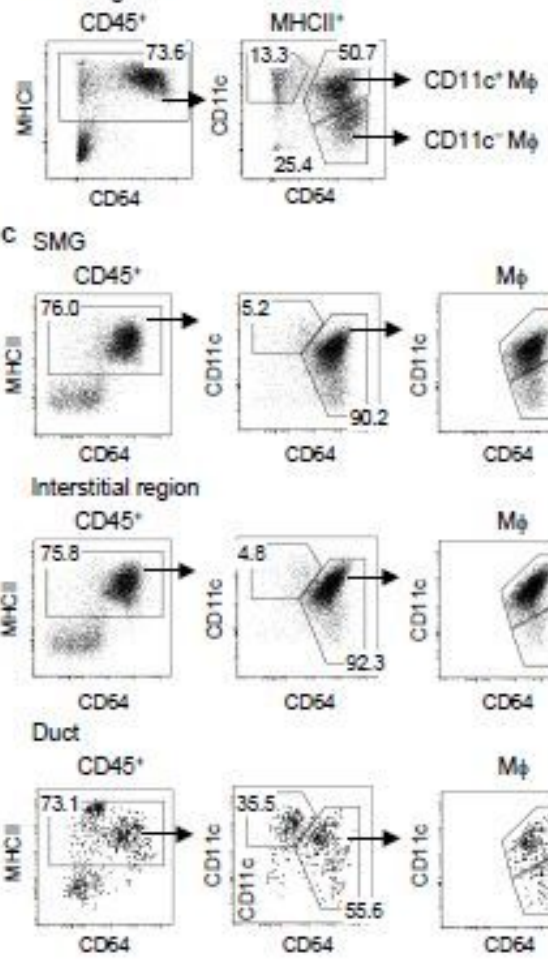

MHCl-

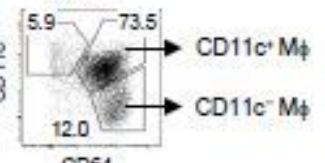

$\mathrm{MHCl}$

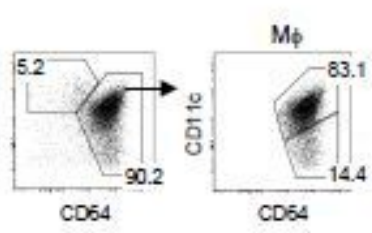

CD64
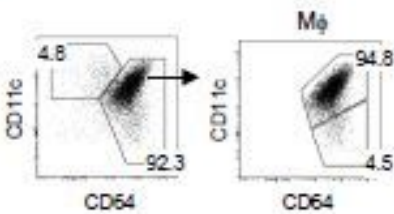

D64
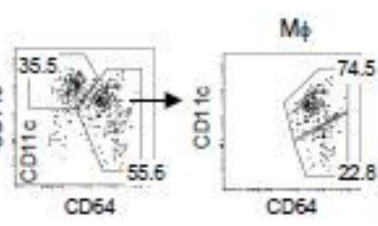

b
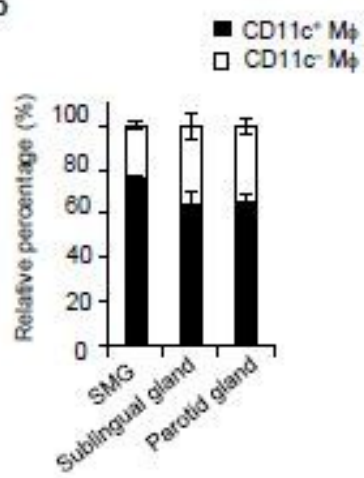

f

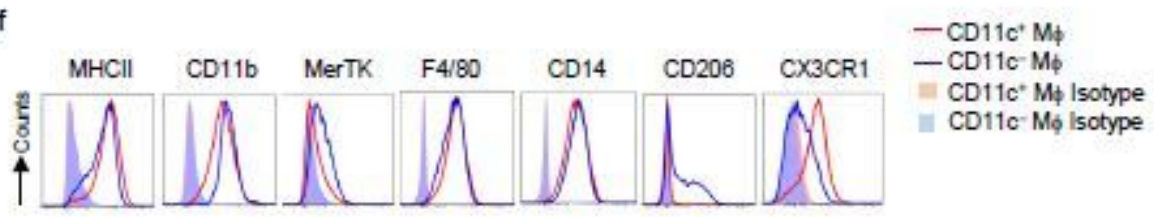

Figure 1

Phenotype and localization of macrophage subsets in steady-state SGs. a Gating strategy to identify macrophage subsets in steady-state SMGs, and sublingual and parotid glands by flow cytometry. Representative plots are shown. b Relative percentages of CD11c+ and CD11c- macrophages in SMGs and the sublingual and parotid glands. Bars represent the mean \pm SD of three mice per group. c-e DCs and macrophages in whole SMGs and in the interstitial region and purified ducts of SMGs were analyzed by flow cytometry. Representative FACS plots (c), the percentages of DCs and macrophages in MHCII+ 
cells (d), and percentages of macrophage subsets (e) are shown. Bars represent the mean $\pm \operatorname{SD}(n=3)$. $\star \star P<0.01$ by the Student's t-test with Welch's correction. $f$ Histograms represent the expression of surface markers. Red and blue lines represent the specific staining of CD11c+ and CD11c- macrophages, respectively, while shaded histograms represent the unstained control. Results are representative of three independent experiments. $M \Phi$, macrophage.

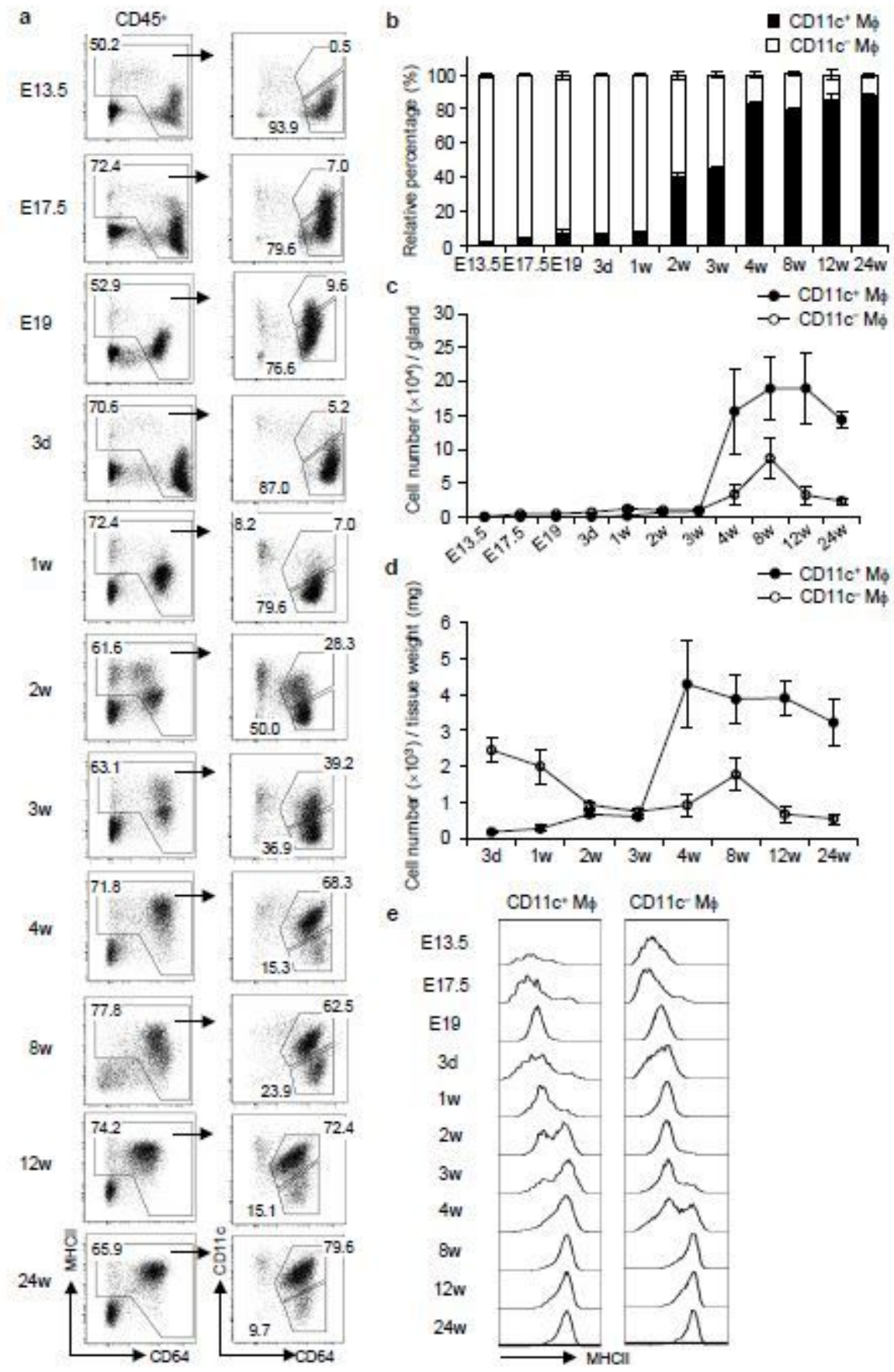

Figure 2 
Age-dependent transition of macrophage subsets in steady-state SMGs. a-e Macrophage subsets in steady-state SMGs from mice at E13.5, E17.5, and E19 (embryo) and at 3 days (newborn) and 1, 2, 3, 4, 8, 12 , and 24 weeks after birth were analyzed by flow cytometry. Representative FACS plots (a), the proportion of CD11c+ and CD11c- macrophages (b), cell numbers per gland (c), cell numbers per tissue weight (d), and representative histograms for the expression of $\mathrm{MHCll}(\mathrm{e})$ are shown. Bars represent the mean $\pm S D(n=3)$. Results are representative of three independent experiments. $M \Phi$, macrophage.

a

Control

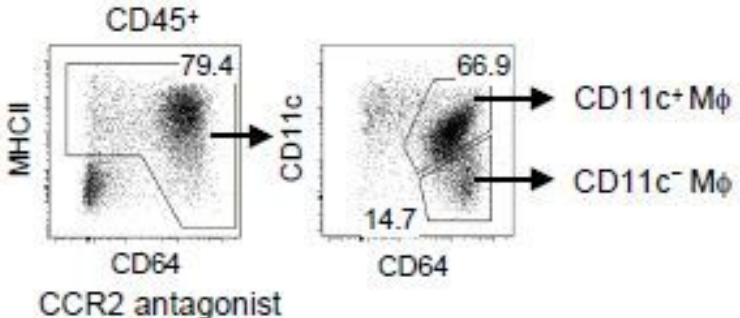

CCR2 antagonist

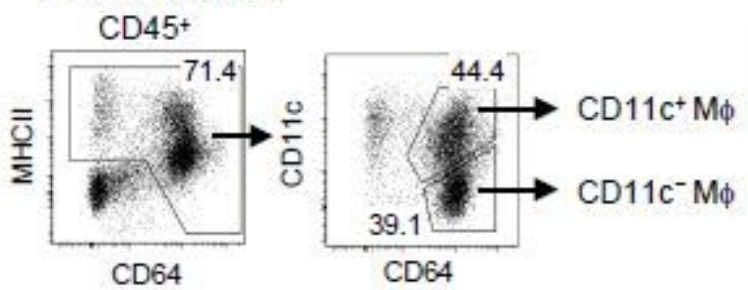

d

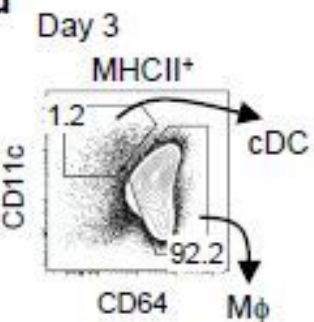

Day 7

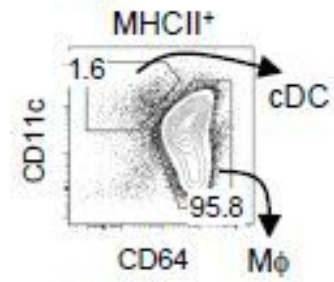

Day 21

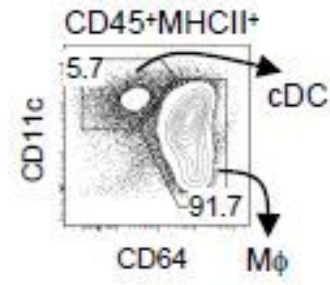

b
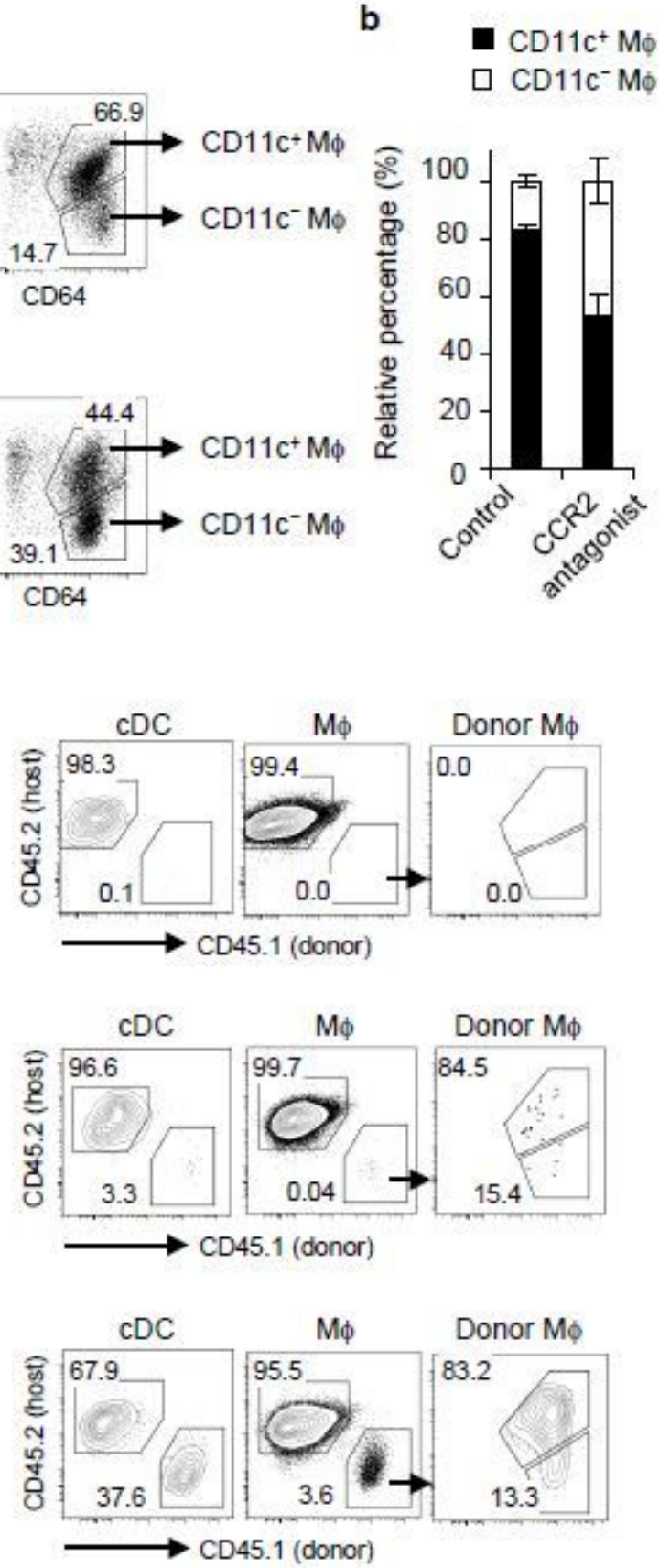

C
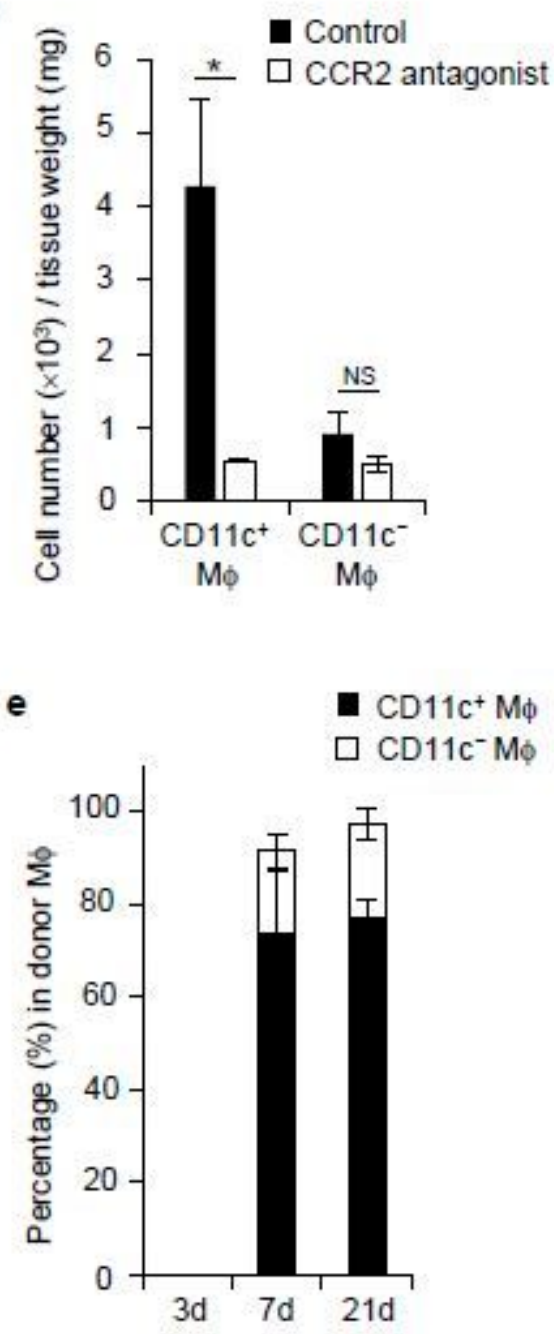

Figure 3 
HSC dependency of macrophage subsets in steady-state SMGs. a-c Macrophage subsets in steady-state SMGs from control or CCR2 antagonist-treated mice. Representative FACS plots (a). Data are representative of three independent experiments. The proportion (b) and absolute numbers (c) of CD11c+ and CD11c- macrophages in steady-state SMGs from control or CCR2 antagonist-treated mice. d, e Sublethally irradiated CD45.2+ mice were adoptively transferred with CD45.1+ BM cells. SMG tissues were harvested at the indicated time points and the percentage of donor-derived (CD45.1+) cDCs and macrophage subsets were analyzed by flow cytometry. Representative FACS plots (d) and the percentages of the CD11c+ and CD11c- subsets in donor macrophages (e) are shown. Bars represent the mean $\pm S D(n=3)$. ${ }^{*}<0.05$ by the Student's t-test with Welch's correction. Results are representative of three independent experiments. MФ, macrophage. NS, not significant.

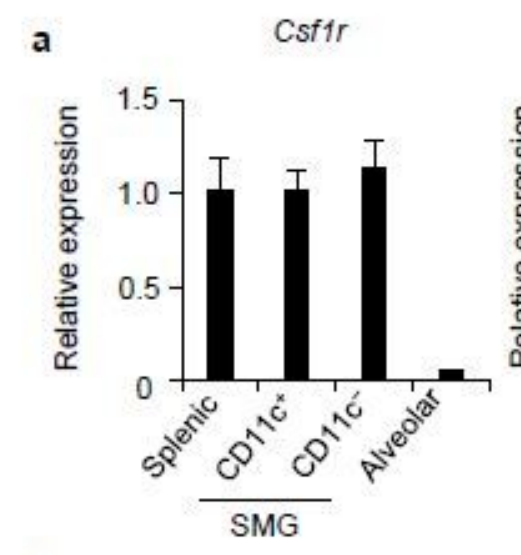

c
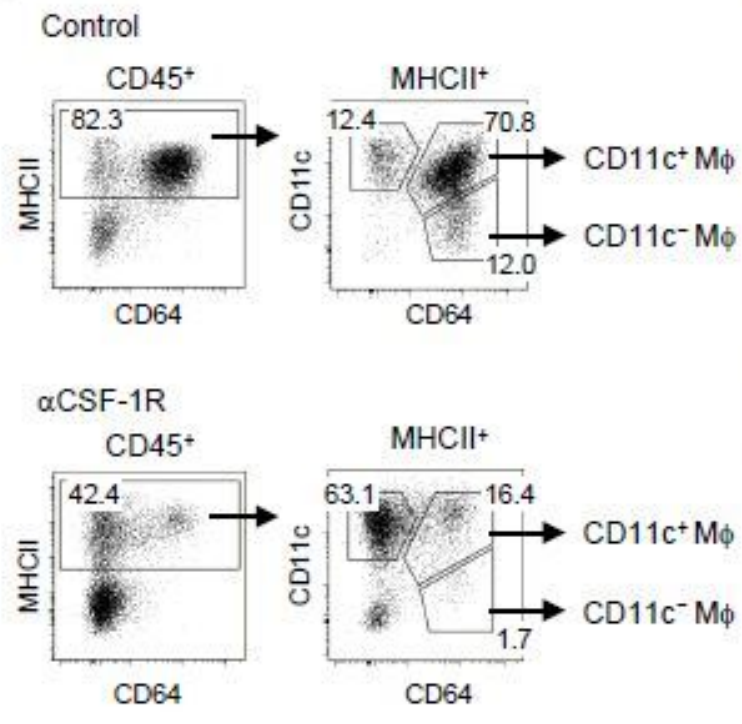

b

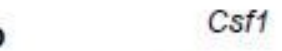

Csf1

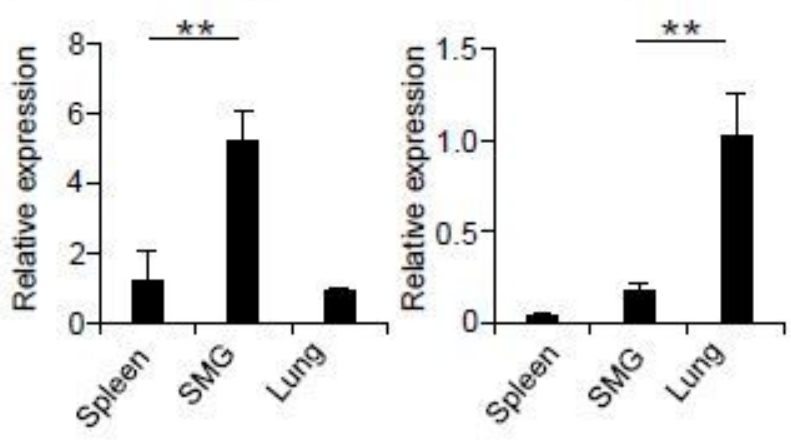

d$$
\text { 政 }
$$

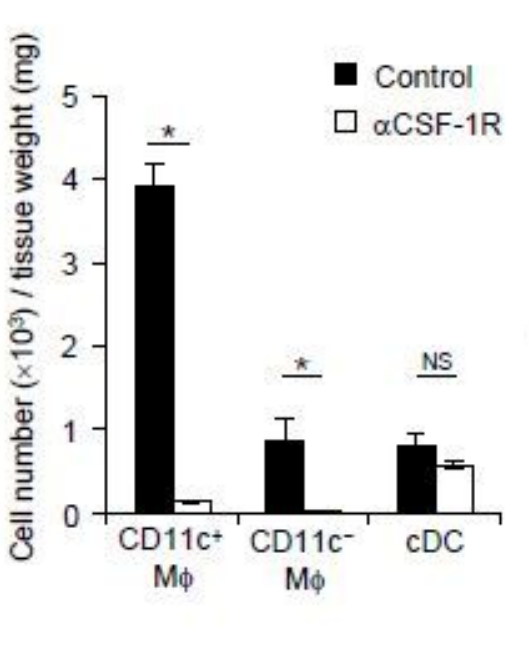

\section{Figure 4}

CSF-1 dependency of macrophage subsets in steady-state SMGs. $a, b$ The mRNA expression levels of Csf1 $r$ and Csf2rb were analyzed by quantitative RT-PCR (a). Splenic and alveolar macrophages were the positive controls for Csf1r and Csf2rb, respectively. Expression levels were normalized to $\beta$-actin levels and expressed as relative expression based on the value of splenic macrophages (Csf1r) or alveolar 
macrophages (Csf2rb). mRNA expression levels of Csf1 and Csf2 in spleen, SMG, and lung tissues (b). The spleen and lungs were positive controls for Csf1 and Csf2, respectively. Expression levels were normalized to $\beta$-actin levels and expressed as relative expression based on the value of the spleen (Csf1) or lungs (Csf2). Results are representative of three independent experiments. c-f Macrophage subsets in steady-state SMGs from control or anti-CSF-1R mAb-injected mice. Representative FACS plots (c), the absolute numbers of CD11c+ and CD11c- macrophages (d), body weight (e), and SMG weight (f) in steady-state SMGs from control or anti-CSF-1R-injected mice are shown. Results are representative of two independent experiments. Bars represent the mean $\pm S D(n=3)$. ${ }^{\star} P<0.01,{ }^{*} P<0.05$ by the Student's ttest with Welch's correction. MФ, macrophage. NS, not significant.

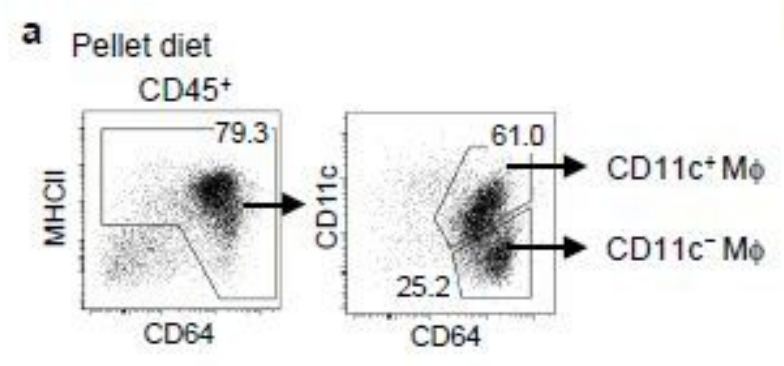

Powdered diet

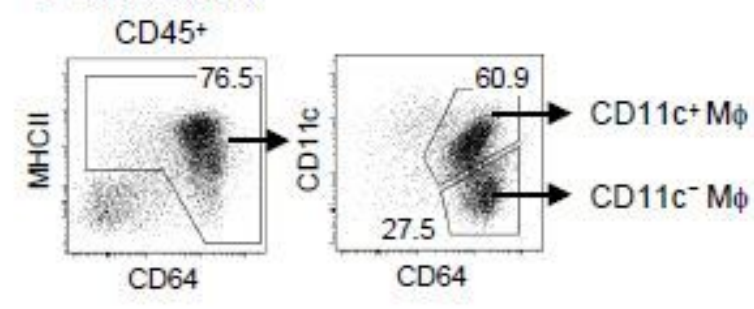

b
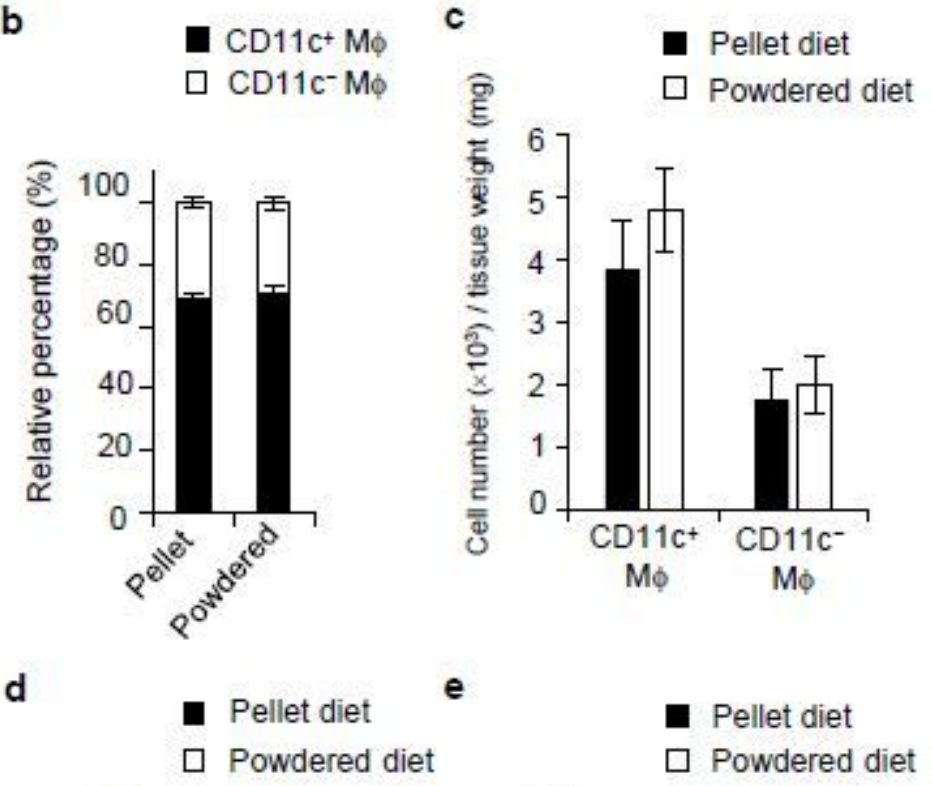

d
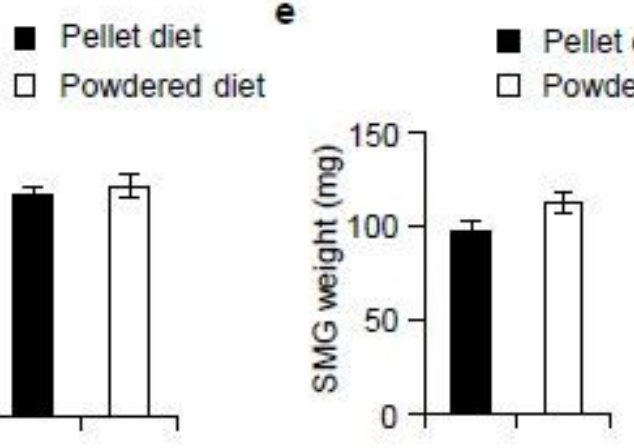

\section{Figure 5}

Effects of the diet form on macrophage subsets in steady-state SMGs. SMGs from mice fed the pellet or powder diet were analyzed by flow cytometry. Representative FACS plots (a), the proportions (b) and absolute numbers of CD11c+ and CD11c- macrophages (c), body weight (d), and SMG weight (e) are shown. Bars represent the mean $\pm S D(n=3)$. Results are representative of three independent experiments. $M \Phi$, macrophage. 


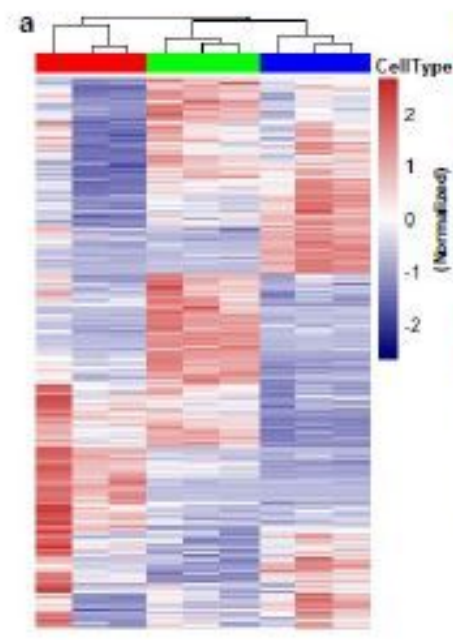

b

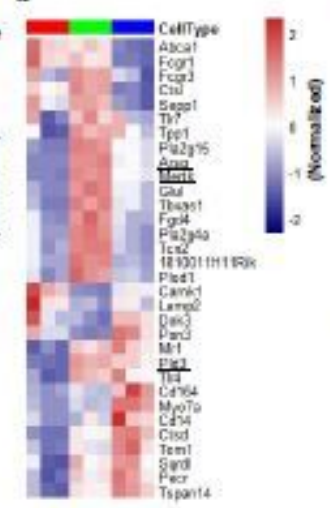

d

Upregulation

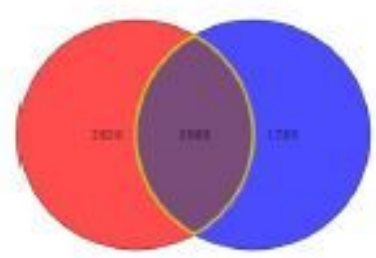

vs. Alveolar Mọ

vs. Splenic M $\phi$

e

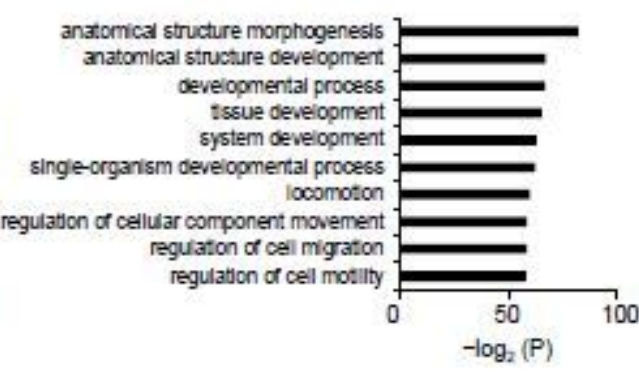

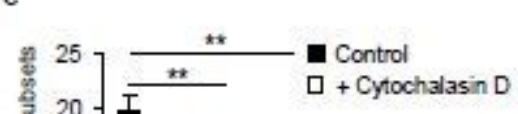

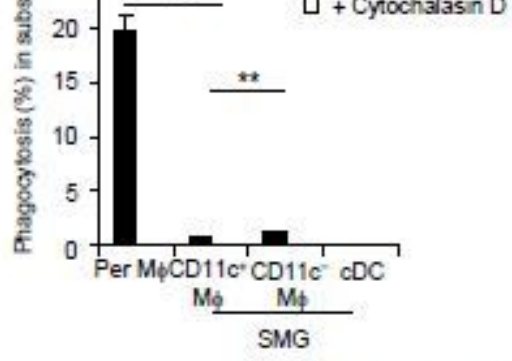

h

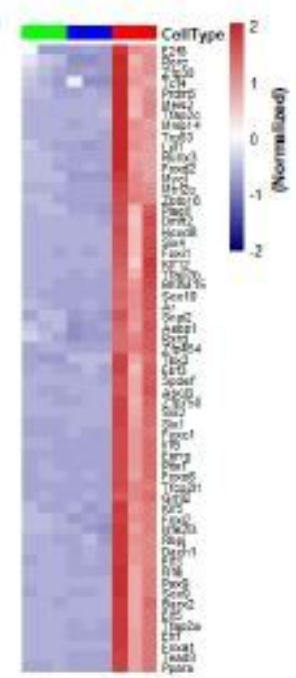

f

g

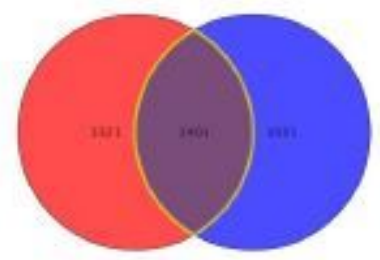

vs. Alveolar Mф̣

vs. Splenic Mф

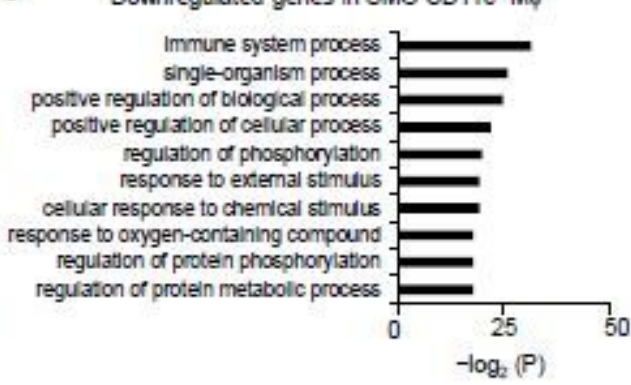

i

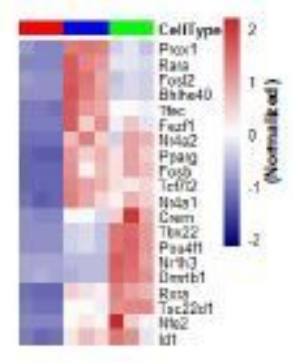

\section{Figure 6}

Functional analysis of SMG macrophages. a, b Heat map of mRNA expression profiles discriminating SMG CD11c+ macrophages from alveolar and splenic macrophages (a). The gene expression profiles of core macrophage signatures10 are shown (b). Cell types include SMG CD11c+ (red), splenic (green), and alveolar macrophages (blue) c Phagocytosis was evaluated by an in vitro assay with pHrodo E. coli BioParticles in the presence or absence of cytochalasin D. Bars represent the mean $\pm S D$. ${ }^{*} P<0.01$ by the Student's t-test with Welch's correction. Results are representative of three independent experiments. d, $f$ Venn diagrams showing differentially expressed genes (significantly up- or down-regulated by 2-fold or more) in SMG CD11c+ macrophages relative to alveolar and splenic macrophages. e, $g$ The most significant GO terms for up-regulated (e) and down-regulated (g) genes in SMG CD11c+ macrophages. 
The top 10 significantly enriched GO terms are shown. h, i Heat maps showing differentially expressed encoding transcription factors (significantly up- or down-regulated by 5 -fold or more) in SMG CD11c+ macrophages (red) relative to splenic (green) and alveolar macrophages (blue). Microarray data were collected from three independent experimental samples for each cell type. $M \Phi$, macrophage.

\section{Supplementary Files}

This is a list of supplementary files associated with this preprint. Click to download.

- SupplementaryFigandTables.pdf 